\title{
Синергетический подход
}

\section{к совершенствованию налогообложения на основе учета технологических и экономических аспектов открытых горных работ}

DOI: http://dx.doi.org/10.18796/0041-5790-2022-1-4-7

\section{литвИн О.И.}

Канд. техн. наук,

дочент ФГБОУ ВО «КузГТУ им. Т.Ф. Горбачева»,

650000, г. Кемерово, Россия,

e-mail:litvinoi@kuzstu.ru

\section{XОРЕШОК A.A.}

Доктор техн. наук, профессор ФГБОУ ВО «КузГТУ им. Т.Ф. Горбачева», 650000, г. Кемерово, Россия,

e-mail:haa.omit@kuzstu.ru

\section{литвИн я.0.}

Канд. техн. наук,

директор Филиала АО УК «Кузбассразрезуголь» «Моховский угольный разрез»,

652661, Кемеровская область, д. Мохово, Россия, e-mail: litvinyao@kuzstu.ru

\section{ТЮЛЕНЕВА Т.A.}

Канд. экон. наук,

дочент ФГБОУ ВО «КузГТУ им. Т.Ф. Горбачева», 650000, г. Кемерово, Россия,

e-mail:krukta@mail.ru

\section{ТЮЛЕНЕВ М.А.}

Канд. техн. наук, дочент ФГБОУ ВО «КузГТУ им. Т.Ф. Горбачева», 650000, г. Кемерово, Россия, e-mail:tma.geolog@kuzstu.ru
При расчете налога на добычу полезных ископаемых в настоящее время ведется учет лишь небольшого количества факторов, что приводит квыхолащиванию системы налогообложения недропользователей и ее укрупненной формализации: не учитывается степень сложности строения разрабатываемых пластов, тектоническое строение карьерного поля и другие неменее значимые индикаторы, характеризующие как технологическую трудность, так и экономическую затратность ведения открытых горных работ. С целью ликвидации этого недостатка в настоящей статье предлагается детализированная классификация, использующая синергетический подход и учитывающая, с одной стороны, разнообразие горно-геологических и горнотехнических условий эксплуатации предприятия, а с другой стороны - степень их влияния на экономические показатели работы разреза.

Ключевые слова: горнодобывающий регион, синергия, недропользование, налог на добычу полезных ископаемых, открытые горные работы, горно-геологические условия, система открытой разработки, потери угля.

Для цитирования: Синергетический подход к совершенствованию налогообложения на основе учета технологических и экономических аспектов открытых горных работ / О.И. Литвин, А.А Хорешок, Я.О. Литвин и др. // Уголь. 2022. № 1. С. 4-7. DOI: 10.18796/0041-57902022-1-4-7.

\section{ВВЕДЕНИЕ}

Ряд существующих нормативных документов, регламентирующих показатели того или иного технологического процесса, был разработан 30-40 и более лет назад и в настоящий момент времени уже не в полной мере отражает накопленный опыт работы горных предприятий [1]. В частности, в методике расчета потерь угля при ведении открытых горных работ [2] формализован расчет потерь лишь для пластов простого строения, выдержанных по мощности и углу залегания; также не учитывается применение 


\section{Взаимосвязь факторов, определяющих условия работы предприятия,} и поправочных коэффициентов на их основе

\begin{tabular}{l}
\multicolumn{1}{c}{ Определяющий фактор } \\
$\begin{array}{l}\text { Горно-геологические, горнотехнические условия } \\
\text { разработки }\end{array}$
\end{tabular}

Производственная мощность разреза, его срок службы

Вскрытие карьерного поля (выбор способа и схемы вскрытия)

Определение вида системы открытой разработки

Подготовка горных пород к выемке (учет строения и свойств пород угленасыщенной и безугольной зон карьерного поля)

Экскаваторно-автомобильный комплекс как главная составная единица всего комплекта оборудования, применяемого (запланированного к применению) на предприятии

Транспортирование горной массы (расположение отвалов - внутренний и/или внешний, дальность откатки и т.д.)

Обогащение добытого угля (расположение обогатительной фабрики или установки, расстояние до нее, учет трудности обогатимости угля и др.)

Рекультивация выработанного пространства карьерного поля и поверхности отвалов

Отдаленность разреза от основных транспортных коммуникаций (связь с основными линиями МПС, расстояние до крупных магистралей и т.д.)

\section{Поправочный коэффициен}

Коэффициент сложности $C_{d}$ (difficulty coefficient), учитывающий индикаторы: сложность строения разрабатываемого пласта (свиты пластов), параметры их залегания, тектоническое строение карьерного поля и т.д.

Временной коэффициент $C_{t}$ (time coefficient), учитывающий срок службы предприятия во взаимоувязке с его годовой производственной мощностью

Коэффициент вскрытия $C_{\text {op }}$ (opening-up coefficient), который зависит от выбранного способа и схемы вскрытия

Коэффициент $C_{m s}$ (mining system coefficient), учитывающий вид системы разработки месторождения

Коэффициент $C_{d b}$ (drilling and blasting coefficient), зависящий от степени сложности ведения буровзрывных работ (принимается, что основным видом подготовки горных пород к выемке является буровзрывной способ)

Коэффициент $C_{s t}$ (shovel and truck coefficient), зависящий от состава экскаваторно-автомобильного комплекса и, как следствие, переменных и постоянных затрат на его содержание, эксплуатацию и ремонт

Коэффициент $C_{t r}$ (transport coefficient), на который влияют параметры автодорог (внутрикарьерных и находящихся за пределами карьерного поля); их категория; уклон (абсолютный и приведенный) и т.д.

Коэффициент $C_{q}$ (quality coefficient), учитывающий качественные характеристики марки добываемого угля (без учета результатов его обогащения)

Коэффициент $C_{r}$ (reclamation coefficient), учитывающий сложность и затраты на проведение рекультивационных работ

Коэффициент $C_{p}$ (peripheral coefficient), учитывающий периферийность (отдаленность) горного предприятия различных типов выемочных машин (например, прямых и обратных гидролопат). Принимая во внимание, что пласты простого строения (по сути, эталонный вариант для расчета) практически отсутствуют на всех угольных месторождениях России, можно констатировать, что на этапе проектирования горных предприятий расчетные нормативы потерь зачастую становятся далеки от возможных реальных значений. Примерно то же можно сказать и о НДПИ, который рассчитывается без приема во внимание современных показателей работы разрезов $[3,4,5]$.

\section{УЧЕТ ТЕХНОЛОГИЧЕСКИХ И ЭКОНОМИЧЕСКИХ АСПЕКТОВ ОТКРЫТЫХ ГОРНЫХ РАБОТ}

С учетом вышесказанного авторами предлагается усовершенствованная методика расчета НДПИ, учитывающая ряд наиболее важных горно-геологических и горнотехнических факторов, напрямую влияющих на экономические показатели работы угольных разрезов, для чего была выполнена классификация этих факторов (табл. 1). Перечень факторов приведен без ранжировки, поскольку данный вопрос подлежит дальнейшему изучению; безусловно, предварительная ранжировка может быть выполнена на основе имеющегося опыта работы разрезов $[6,7,8,9]$ и на основе формальной логики [10], однако точных значений на данном этапе получить невозможно без детального анализа гиперпула статистических данных.
На основе данной обобщающей таблицы (см. табл. 1) авторами предлагается матричная модель взаимоувязки индикаторов и субкоэффициентов, более подробно отражающих тот или иной фактор. Индикаторы призваны учесть многообразие условий ведения горных работ [11] и увязывать их с платежами за пользование недрами.

В табл. 2 приведен пример матричной модели для коэффициента сложности $C_{d^{\prime}}$ отражающего степень сложности горно-геологических условий разработки месторождения.

По такой же системе предполагается провести анализ и для всех остальных коэффициентов, указанных в табл. 1.

\section{ЗАКЛЮЧЕНИЕ}

С целью определения степени влияния того или иного индикатора на значение итогового результата необходимо выполнить подробный анализ горно-геологических и горнотехнических условий разработки существующих и проектируемых разрезов и, базируясь на полученной информации, определить частоту проявления индикаторов в условиях Кузбасса, что позволит получить их реальные значения и на этой основе обосновать величины поправочных коэффициентов к расчету НДПИ. 


\section{Взаимоувязка индикаторов коэффициента сложности $C_{d}$ с идентификаторами субкоэффициентов}

\begin{tabular}{|c|c|}
\hline $\begin{array}{c}\text { Индикатор } \\
\text { коэффициента } \\
\text { сложности } C_{d}\end{array}$ & $\begin{array}{c}\text { Идентификатор } \\
\text { суб-коэффициента }\end{array}$ \\
\hline \multirow{2}{*}{$\begin{array}{l}\text { Мощность } \\
\text { отрабатываемого } \\
\text { пласта }\end{array}$} & Геологическая классификация \\
\hline & $\begin{array}{l}\text { Классификация при открытой } \\
\text { геотехнологии }\end{array}$ \\
\hline \multirow{3}{*}{$\begin{array}{l}\text { Угол залегания } \\
\text { пласта }\end{array}$} & Классификация по ВНИМи \\
\hline & Классификация по акад. В.В. Ржевскому \\
\hline & Классификация по проф. В.Ф. Колесникову \\
\hline \multirow{4}{*}{$\begin{array}{l}\text { Структура } \\
\text { карьерного поля }\end{array}$} & Одиночный пласт \\
\hline & Свита сближенных пластов \\
\hline & Свита рассредоточенных пластов \\
\hline & Свита пластов смешанного залегания \\
\hline \multirow{3}{*}{$\begin{array}{l}\text { Структура } \\
\text { угольного пласта } \\
\text { (пластов) }\end{array}$} & Пласт (пласты) простого строения \\
\hline & Пласт (пласты) сложного строения \\
\hline & Пласт (пласты) весьма сложного строения \\
\hline \multirow{3}{*}{$\begin{array}{l}\text { Тектоника } \\
\text { карьерного поля }\end{array}$} & Наличие пликативных нарушений \\
\hline & Наличие дизъюнктивных нарушений \\
\hline & Наличие зон «горельника» и т.д. \\
\hline \multirow{3}{*}{$\begin{array}{l}\text { Мощность наносов } \\
\text { (четвертичных } \\
\text { отложений) }\end{array}$} & Наносы малой мощности \\
\hline & Наносы средней мощности \\
\hline & Наносы большой мощности \\
\hline \multirow{4}{*}{$\begin{array}{l}\text { Рельеф } \\
\text { поверхности } \\
\text { участка } \\
\text { карьерного поля }\end{array}$} & Равнинный \\
\hline & Слабовсхолмленный \\
\hline & Пересеченный \\
\hline & Гористый \\
\hline \multirow{3}{*}{$\begin{array}{l}\text { Обводненность } \\
\text { участка недр }\end{array}$} & Малые водопритоки \\
\hline & Средние водопритоки \\
\hline & Обильные водопритоки \\
\hline
\end{tabular}

\section{Список литературы}

1. Таразанов, И.Г., Губанов Д.А. Итоги работы угольной промышленности России за январь-июнь 2021 года // Уголь. 2021. № 9. C. 25-36. DOI: 10.18796/0041-5790-2021-9-25-36.
2. Указания по нормированию, планированию и экономической оценке потерь угля в недрах по Кузнецкому бассейну: Открытые работы. Л.: ВНИМИ, 1991. 23 с.

3. Tax aspects of mining companies in V4 countries / J. Simonidesová, Z. Kudlová, J. Lukáč et al. // Acta Montanistica Slovaca. 2021. Vol. 26 (1). P. 35-46.

4. Tyuleneva T., Moldazhanov M. The Use of Environmental Taxation Instruments in Order to Ensure Sustainable Development of Mining Region // E3S Web of Conferences. 2020. No 174. Article 04061.

5. Analysis of investments in the mining industry / M. Cehlár, P. Rybár, J. Mihók et al. // Journal of Mining and Geotechnical Engineering. 2020. No 1. P. 4-31.

6. Тюленева Е.А., Лесин Ю.В., Литвин Я.О. Исследование технологии отработки угленасыщенных зон на разрезах Кузбасса простыми и сложными забоями // Техника и технология горного дела. 2019. № 1(4). С. 35-50.

7. Kolesnikov V.F., Cehlár M., Tyuleneva E.A. Overview of excavation and loading operations in the coal-bearing zones at Kuzbass open pit mines // Journal of Mining and Geotechnical Engineering. 2018. No 2. P. 36-49. DOI: 10.26730/2618-74342018-2-36-49.

8. Милый С.М. Оценка технологий отработки крутонаклонных угольных месторождений Кузбасса // Техника и технология горного дела. 2020. № 1. С. 45-73. DOI: 10.26730/2618-7434-2020-1-45-73.

9. Theoretical Features of Rope Shovels and Hydraulic Backhoes Using at Open Pit Mines / A. Strelnikov, S. Markov, L. Rattmann et al. // E3S Web of Conferences. 2018. Vol. 41. Article 01003.

10. Стенли Джевонс. Основы науки: Трактат о логике и научном методе. СПб: Издательство Л.Ф. Пантелеев, 1881. $713 \mathrm{c}$.

11. Perspectives for the transportless mining technology in siberia and far east coal deposits / S. Markov, J. Janočko, M. Tyulenev et al. // E3S Web of Conferences. 2019. Vol. 105. Article 01021.

Original Paper

ECONOMIC OF MINING

UDC 336.201:622.271.3 @ O.I. Litvin, A.A. Khoreshok, Ya.O. Litvin, T.A. Tyuleneva, M.A. Tyulenev , 2022

ISSN 0041-5790 (Print) • ISSN 2412-8333 (Online) • Ugol' - Russian Coal Journal, 2022, № 1, pp. 4-7

DOI: http://dx.doi.org/10.18796/0041-5790-2022-1-4-7

\section{Title}

SYNERGETIC APPROACH TO IMPROVEMENT TAXATION BASED ON ACCOUNTING

OF TECHNOLOGICAL AND ECONOMIC ASPECTS OF OPEN-PIT MINING

\section{Authors}

Litvin O.I. ${ }^{1}$, Khoreshok A.A. ${ }^{\text {, }}$ Litvin Ya.O. ${ }^{2}$, Tyuleneva T.A. ${ }^{1}$, Tyulenev M.A. ${ }^{1}$

${ }^{1}$ Gorbachev Kuzbass State Technical University (KuzSTU), Kemerovo, 650000, Russian Federation

${ }^{2}$ Branch of JSC «UK Kuzbassrazrezugol» Mokhovsky Open Pit Mine, Mokhovo settlement, Kemerovo region, 652661, Russian Federation

\section{Authors Information}

Litvin O.I., PhD (Engineering), Associate Professor, e-mail: litvinoi@kuzstu.ru Khoreshok A.A., Doctor of Engineering Sciences, Professor,

e-mail: haa.omit@kuzstu.ru

Litvin Ya.O., PhD (Engineering), Director, e-mail: litvinyao@kuzstu.ru

Tyuleneva T.A., PhD (Economic), Associate Professor, e-mail: krukta@mail.ru

Tyulenev M.A., PhD (Engineering), Associate Professor,

e-mail: tma.geolog@kuzstu.ru

\section{Abstract}

When calculating the mineral extraction tax, currently only a small number of factors are taken into account, which leads to weakening of the system of taxation of subsoil users and its enlarged formalization: the degree of complexity of the structure of developed seams, the tectonic structure of the quarry field and other equally important indicators, which characterize both technological difficulty and economic cost of open pit mining are not taken into account. In order to eliminate this shortcoming, this article proposes a 
detailed classification that uses a synergistic approach and considers, on the one hand, the diversity of mining-geological and mining-technical operating conditions of the enterprise, and on the other hand, the degree of their influence on the economic performance of the open pit.

\section{Keywords}

Mining region, Synergy, Subsoil use, Mineral extraction tax, Surface mining, Mining and geological conditions, Surface mining system, Coal losses

\section{References}

1. Tarazanov I.G. \& Gubanov D.A. Russia's coal industry performance for january - june, 2021. Ugol', 2021, (9), pp. 25-36. (in Russ.). DOI: 10.18796/00415790-2021-9-25-36.

2. Instructions on regulation, planning and economic evaluation of coal losses in earth depths of Kuznetsk basin: Surface mining. L.: VNIMI, 1991, 23 p. (in Russ.).

3. Simonidesová J., Kudlová Z., Lukáč J. et al. Tax aspects of mining companies in V4 countries. Acta Montanistica Slovaca, 2021, Vol. 26, pp. 35-46.

4. Tyuleneva T. \& Moldazhanov M. The Use of Environmental Taxation Instruments in Order to Ensure Sustainable Development of Mining Region. E3S Web of Conferences, 2020, (174), Article 04061.

5. Cehlár M., Rybár P., Mihók J.et al. Analysis of investments in the mining industry. Journal of Mining and Geotechnical Engineering, 2020, (1), pp. 4-31. 6. Tyuleneva E.A., Lesin Yu.V. \& Litvin Ya.O. Reasearch of simple and complex pitface technology in the coal bearing zones at Kuzbass openpit mines. Tekhnika i tekhnologiya gornogo dela, 2019, (1). pp. 35-50. (in Russ.)
7. Kolesnikov V.F., Cehlár M. \& Tyuleneva E.A. Overview of excavation and loading operations in the coal-bearing zones at Kuzbass open pit mines. Journal of Mining and Geotechnical Engineering, 2018, (2), pp. 36-49. DOI: 10.26730/26187434-2018-2-36-49.

8. Milyi S.M. Estimation of pitface technologies in steepslope coalfields at Kuzbass openpit mines. Tekhnika i tekhnologiya gornogo dela, 2020, (1), pp. 45-73. (in Russ.). DOI: 10.26730/2618-7434-2020-1-45-73.

9. Strelnikov A., Markov S., Rattmann L. et al. Theoretical Features of Rope Shovels and Hydraulic Backhoes Using at Open Pit Mines. E3S Web of Conferences, 2018, Vol. 41, Article 01003.

10. Stenli Dzhevons. Science fundamentals: treatise on logic and science method. Sankt-Peterburg, L.F. Panteleev Publ., 1881, 713 p. (in Russ.).

11. Markov S., Janočko J., Tyulenev M. et al. Perspectives for the transportless mining technology in siberia and far east coal deposits. E3S Web of Conferences, 2019, Vol. 105, Article 01021.

\section{For citation}

Litvin O.I., Khoreshok A.A., Litvin Ya.O., Tyuleneva T.A. \& Tyulenev M.A. Synergetic approach to improvement taxation based on accounting of technological and economic aspects of open-pit mining. Ugol', 2022, (1), pp. 4-7. (In Russ.). DOI: 10.18796/0041-5790-2022-1-4-7.

\section{Paper info}

Received November 17, 2021

Reviewed December 2, 2021

Accepted December 15, 2021

\section{Бородинский разрез провел экскурсию}

\section{для молодых специалистов горного дела}

Очередных экскурсантов принял Бородинский разрез им. М.И. Щадова (предприятие СуэК Андрея Мельниченко в Красноярском крае). Ими стали участники второго этапа IX Omкрытого регионального чемпионата профессионального мастерства «Молодые профессионалы», который проходил в Ириинском техникуме горных разработок им. В.П. Астафьева. С техникумом горных разработок крупнейшее предприятие открытой угледобычи связывают многолетние партнерские отношения.

«Многие выпускники техникума трудятся на нашем предприятии, студенты постоянно проходят на разрезе производственную практику и показывают очень высокую профессиональную подготовку, - уточнил заместитель управляющего Бородинским разрезом по персоналу и административным вопросам Виктор Бирилкин. - И то, что Иршинский техникум стал площадкой для соревнований такого уровня, безусловно, говорит об авторитете его преподавателей и отличном техническом оснащении».

Посещение разреза-гиганта стало частью познавательной программы профессионального чемпионата. Прежде всего, молодые люди соревновались в устранении неисправностей в дизельных двигателях, гидравлических, электрических системах хода бульдозера, экскаватора, автогрейдера, фронтального погрузчика. Затем для участников была организована онлайн-трансляция студии «Открытые мастерские WorldSkills» на тему «Кадровые потребности экономики края и приоритеты модернизации системы профессионального образования». Экскурсия на Бо- родинский разрез стала финальной точкой программы.

«У нас тоже есть угольный разрез, и мы имеем представление, как добывается уголь, но величина и мощь Бородинского разреза просто поражают, - признались гости с Сахалина, студенты политехнического центра, осмотрев горное поле со смотровой площадки. Таких залежей «черного золота», столько техники, занятой на его добыче и транспортировке, мы еще не видели. Все это приводит в настоящий восторг!» Также гости проехали по знаковым местам Бородино, побывали в Музее города и Бородинского разреза под открытым небом.

Предприятия СУЭК регулярно проводят экскурсии и дни открытых дверей для молодежи. Цель такого знакомства с производством - профессиональная ориентация, привлечение молодых специалистов в горную отрасль. В год 20-летия на угольных разрезах СУЭК в крае побывали уже сотни гостей - от студентов и школьников до педагогов.

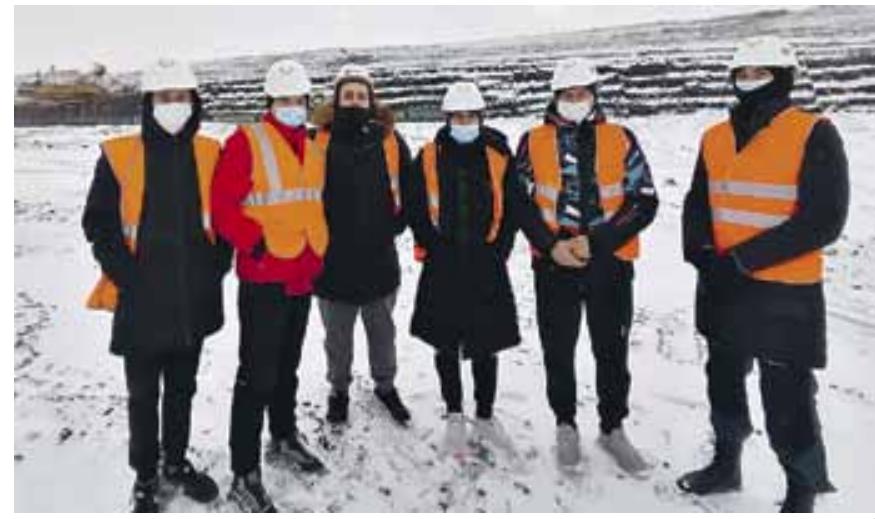

